\section{Commentary: Delirium prevention in cardiac surgery: Simplicity is beauty}

\author{
Edward Buratto, MBBS, PhD, FRACS, a,b,c \\ Antonia Schulz, MD, and \\ Igor E. Konstantinov, MD, PhD, FRACS ${ }^{\mathrm{a}, \mathrm{b}, \mathrm{c}, \mathrm{d}}$
}

Delirium is a common complication following cardiac surgery, occurring in more than $20 \%$ of patients, and contributes to mortality, long-term cognitive decline, loss of independence, and increased health care costs. ${ }^{1,2}$ As the population undergoing cardiac surgery continues to age, the rate of delirium will inevitably increase. In an effort to reduce the impact of delirium on patients undergoing cardiac surgery, a broad range of interventions has been evaluated, from improved screening and diagnostic tools, ${ }^{1,2}$ intraoperative near-infrared spectroscopy monitoring, ${ }^{3}$ pharmacotherapy, ${ }^{4}$ and specific surgical techniques, such as selective antegrade cerebral perfusion for arch surgery ${ }^{5}$ and anaortic techniques for coronary artery bypass surgery. ${ }^{6}$ However, none of these strategies has proven to significantly improve rates of delirium nor achieved widespread adoption.

In this issue of the Journal, Enomoto and colleagues ${ }^{7}$ report their experience with a novel delirium prevention program, the delirium team approach (DELTA). The DELTA program comprises 3 components: education for physicians, nursing, and allied health staff; changes to preprinted medication orders to avoid medications known to exacerbate delirium; and screening and assessing the risk

From the a Department of Cardiac Surgery, Royal Children's Hospital; ${ }^{b}$ Department of Paediatrics, University of Melbourne; 'Heart Research Group, Murdoch Children's Research Institute; and ${ }^{\mathrm{d}}$ Melbourne Centre for Cardiovascular Genomics and Regenerative Medicine, Melbourne, Australia.

Disclosures: The authors reported no conflicts of interest.

The Journal policy requires editors and reviewers to disclose conflicts of interest and to decline handling or reviewing manuscripts for which they may have a conflict of interest. The editors and reviewers of this article have no conflicts of interest.

Received for publication Aug 3, 2021; revisions received Aug 3, 2021; accepted for publication Aug 3, 2021; available ahead of print Aug 8, 2021.

Address for reprints: Igor E. Konstantinov, MD, PhD, FRACS, Royal Children's Hospital, Flemington Rd, Parkville, Victoria 3052, Australia (E-mail: igor. konstantinov@rch.org.au).

J Thorac Cardiovasc Surg 2023;165:1882-3

0022-5223/ $\$ 36.00$

Crown Copyright $@ 2021$ Published by Elsevier Inc. on behalf of The American Association for Thoracic Surgery

https://doi.org/10.1016/j.jtcvs.2021.08.003

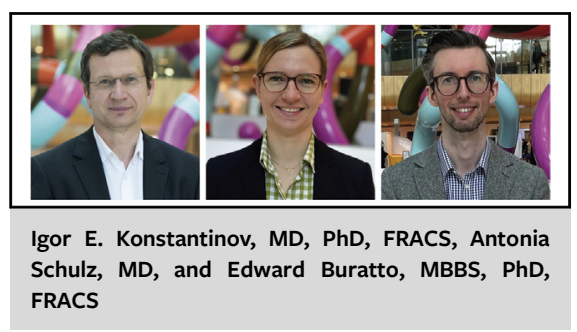

CENTRAL MESSAGE

A systematic team-based program of delirium prevention may significantly improve outcomes after cardiac surgery.

factors of delirium. In a propensity score-matched analysis, the authors demonstrated that the program was associated with a significant decrease in the occurrence of delirium, shorter intensive care and hospital stays, and lower hospital costs. They also demonstrated a decreased rate of discharge to health care facilities following introduction of the DELTA program, albeit in the unmatched cohort.

The beauty of the program reported by Enomoto and colleagues ${ }^{7}$ is its simplicity. It does not require expensive or sophisticated equipment, there are no new medications that require testing and regulatory approval, and it does not involve complex surgical techniques with a learning curve. All the strategies employed are readily available within any health care system: education, rational prescribing, and screening for delirium. It is remarkable that systematic application of these simple principles appears to be associated with such a substantial reduction in postcardiac surgery delirium. Enomoto and colleagues ${ }^{7}$ rightly point out that the program increases the burden on already-stretched medical, nursing, and allied health staff. This will require staff to attend additional education sessions and may necessitate increased staffing or longer hours. Additionally, it should be noted that the rate of delirium in the population was very high; this may be related to the high proportion of patients undergoing aortic surgery, which is known to be associated with greater risks of delirium. ${ }^{6}$ It remains to be seen whether the program will be effective in the general population of patients undergoing cardiac surgery, in whom the rate of delirium is considerably lower.

Ideally, a multicenter randomized control trial would investigate the efficacy of the DELTA program. In the meantime, the work of Enomoto and colleagues ${ }^{7}$ demonstrates the potential impact of an easily introduced 
preventative program in reducing the burden of delirium after cardiac surgery. In an age of rapid technological innovations, it is important that we do not overlook the simple measures that may make the biggest difference to patient care and the cost-effectiveness!

\section{References}

1. Dubiel C, Hiebert BM, Stammers AN, Sanjanwala RM, Tangri N, Singal RK, et al. Delirium definition influences prediction of functional survival in patients oneyear postcardiac surgery. J Thorac Cardiovasc Surg. July 16, 2020;165:1873-81.

2. Chang Y, Ragheb SM, Oravec N, Kent D, Nugent K, Cornick A, et al. Diagnostic accuracy of the "4 A's Test" delirium screening tool for the postoperative cardiac surgery ward. J Thorac Cardiovasc Surg. 2020;165:1873-81.

3. Uysal S, Lin HM, Trinh M, Park CH, Reich DL. Optimizing cerebral oxygenation in cardiac surgery: a randomized controlled trial examining neurocognitive and perioperative outcomes. J Thorac Cardiovasc Surg. 2020;159:943-53

4. Turan A, Duncan A, Leung S, Karimi N, Fang J, Mao G, et al; DECADE Study Group. Dexmedetomidine for reduction of atrial fibrillation and delirium after cardiac surgery (DECADE): a randomised placebo-controlled trial. Lancet. 2020; 396:177-85.

5. Szwed K, Pawliszak W, Szwed M, Tomaszewska M, Anisimowicz L, Borkowska A. Reducing delirium and cognitive dysfunction after off-pump coronary bypass: a randomized trial. J Thorac Cardiovasc Surg. 2021;161: 1275-82.

6. Peterson MD, Garg V, Mazer CD, Chu MWA, Bozinovski J, Dagenais F, et al ACE CardioLink-3 Trial Working Group. A randomized trial comparing axillary versus innominate artery cannulation for aortic arch surgery. J Thorac Cardiovasc Surg. 2020;165:1873-81

7. Enomoto K, Kosaka S, Kimura T, Matsubara M, Kitada Y, Mieno M, et al. Prevention of postoperative delirium after cardiovascular surgery: a team-based approach. J Thorac Cardiovasc Surg. 2023;165:1873-81.e2.
See Article page 1873 .

\section{Commentary: Teamwork is dreamwork}

Kevin P. Landolfo, MD, MSc, ${ }^{\mathrm{a}, \mathrm{b}}$ and Sean P. Kiley, MD ${ }^{\text {a,c }}$

Delirium (defined as acute brain dysfunction, characterized by a transient, fluctuating course of inattention, impaired consciousness, and disordered cognition) constitutes the most common complication following cardiac surgery. ${ }^{1}$ Previous studies found that postoperative delirium is associated with adverse outcomes, including death, cognitive decline, and loss of functional independence in the early postoperative period as well as long-term cognitive decline and increased mortality. ${ }^{2-5}$ The reported incidence of delirium ranges from $8 \%$ to $50 \%$ postcardiac surgery; however, the diagnosis remains challenging. ${ }^{1}$ Despite this high incidence, treatment strategies remain incompletely

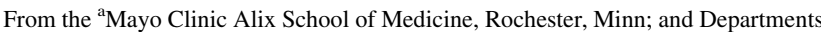
of ${ }^{b}$ Cardiothoracic Surgery and ${ }^{c}$ Critical Care Medicine, Anesthesiology, Mayo Clinic, Jacksonville, Fla.

Disclosures: The authors reported no conflicts of interest.

The Journal policy requires editors and reviewers to disclose conflicts of interest and to decline handling or reviewing manuscripts for which they may have a conflict of interest. The editors and reviewers of this article have no conflicts of interest.

Received for publication July 30, 2021; revisions received July 30, 2021; accepted for publication Aug 3, 2021; available ahead of print Aug 8, 2021.

Address for reprints: Kevin P. Landolfo, MD, MSc, Mayo Clinic, 4500 San Pablo Rd,

Jacksonville, FL 32224 (E-mail: Landolfo.kevin@mayo.edu).

J Thorac Cardiovasc Surg 2023;165:1883-4

$0022-5223 / \$ 36.00$

Copyright (c) 2021 by The American Association for Thoracic Surgery

https://doi.org/10.1016/j.jtcvs.2021.08.002
}

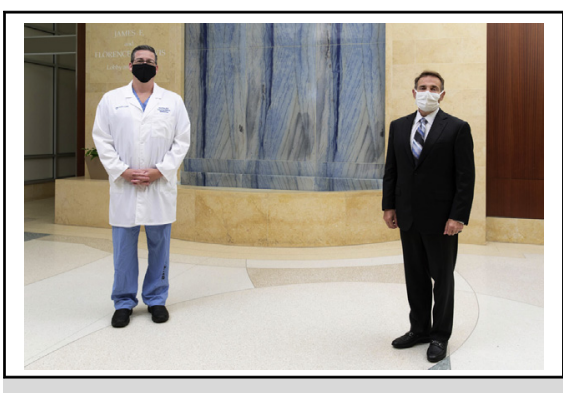

Sean P. Kiley, MD, and Kevin P. Landolfo, MD, MSc

CENTRAL MESSAGE

Delirium is a common complica-

tion after cardiac surgery. A

focused, multidisciplinary post-

defined. In the current issue of

the Journal,

Enomoto and colleagues $^{6}$

operative approach may

decrease the incidence of

delirium and improve postoper-

ative outcomes.

describe a single-institution, retrospective study following implementation of the Delirium Team Approach (DELTA) Program in 302 patients who underwent cardiovascular surgery. The DELTA program, described by Ogawa and colleagues in patients with malignancy, comprises a multidisciplinary, patient-centric program that lowers the incidence of delirium.

The DELTA program includes delirium education for physicians, nurses, therapists, and pharmacists; risk factor screening and delirium assessment; order modification toward evidence-based medications used for sleep 